\title{
EFFECT OF RUMEN-PROTECTED LYSINE (HYDROXY METHYL LYSINE) SUPPLEMENTATION ON PERFORMANCE AND BLOOD METABOLITES IN BARKI SHEEP
}

\author{
E. A. Elwakeel ${ }^{*}$, H.M. El-Zaiat ${ }^{1}$ and A. S. Morsy ${ }^{2}$ \\ ${ }^{1}$ Department of Animal and Fish Production, Faculty of Agriculture, Alexandria University, Alexandria \\ 21545, Egypt \\ ${ }^{2}$ Livestock Research Department, Arid Land Research institute, city of scientific Research and \\ Technological Applications, New Borg El-Arab, Alexandria, Egypt
}

* Corresponding author: P.O. Box 21545, Alex.Egypt.emankeel@yahoo.com

(Received 6/11/2018, accepted 19/12/2018)

\section{SUMMARY}

$\mathrm{E}$ ffect of rumen-protected lysine in the form of Hydroxyl methyl lysine (HML) on average daily gain (ADG), dry matter intake (DMI), nutrient digestibility, nitrogen balance blood metabolites, were evaluated in two experiments using growing Barki lambs. In first experiment, fifteen lambs were housed individually and assigned into three equal groups fed on basal diet (no lysine-control), free lysine (positive control, F-LYS) and protected lysine (P-LYS) equivalent to $3 \mathrm{~g} / \mathrm{d}$ of lysine. The experiment lasted for 10 week to evaluate feed intake, ADG and blood metabolites. No effect $(P>0.05)$ of treatment on ADG, DMI and feed efficiency was observed. Whereas, treatment $\times$ time interaction tendency $(P=0.07)$ as showed an increased in ADG as lysine supplemented as P-LYS compared to F-LYS $(P=0.05)$ and control $(P<0.05)$ at the last 2 weeks. No effect $(P>0.05)$ of treatment was observed on serum total protein (TP), albumin (Alb), globulin (Glob), urea, glucose $(\mathrm{G})$, cholesterol $(\mathrm{CH})$ and triglycerides $(\mathrm{TG})$ concentrations. However, treatment $\times$ time interaction $(P=0.06)$ tendency existed as P-LYS increased $(P<0.05) \mathrm{TP}$, Alb and Glob only at wk. 2 and reduced $(P<0.05)$ serum urea only at the last 2 weeks. Further, no treatment effect $(P>0.05)$ was found on rumen ammonia nitrogen $\left(\mathrm{NH}_{3}-\mathrm{N}\right), \mathrm{pH}$ and protozoa numbers. In Exp.2, (digestibility trial), twelve lambs from Exp.1 were kept in metabolic cages and received their respective treatments for 7 days as collection period. No response $(P>0.05)$ to P-LYS supplementation was observed on nutrient digestibility of dry matter (DM), organic matter (OM), crude protein $(\mathrm{CP})$, neutral detergent fibre (NDF) and acid detergent fibre (ADF) compared to F-LYS and control. A tendency $(P=0.09)$ for treatment on nitrogen balance $(\mathrm{NB})$ and retained nitrogen (RN, $P=0.06)$ was found. P-LYS increased $(P=0.05) \mathrm{NB}$ to $7.1 \pm 0.14 \mathrm{vs}$. $4.8 \pm 0.3 \mathrm{~g} / \mathrm{d}$ and $\mathrm{RN}(P<0.05)$ from 37.9 vs. $25.59 \%$ in the control. However, P-LYS did not improve lambs performance under the basal diet fed that might have not been deficient enough in LYS amino acid, the improved ADG and decreased plasma urea at the last two weeks along with the slight improvement in NB and RN indicates the P-LYS has a potential under specific feeding regimes.

Keywords: lysine; sheep; nitrogen balance; average daily gain

\section{INTRODUCTION}

Providing ruminants with protein that contains ideal amino acids profile that match their requirement is very challenging due to fermentation of protein by rumen microbes results in changing the profile of intestinal amino acids (AA) that become readily available for intestinal absorption (Titgemeyer, 2003). Several studies have reported that methionine and lysine are most limiting AA for protein deposition in ruminant's growth (Merchen and Titgemeyer, 1992). This is because methionine and lysine are the most limiting AA in microbial protein synthesis in growing sheep (Nimrick et al., 1970 and Richardson and Hatfield, 1978). Also, the typical diet for ruminants normally contains lower concentrations of lysine and methionine (Schwab, 1995). The type of the diet used to feed ruminants determines whether methionine or lysine is the first limiting AA (Rulquin and Verite, 1993 and Schwab et al., 1992). 


\section{Elwakeel et al.}

Lysine was found to be the first limiting AA in corn-based diets, while methionine is the first limiting AA in legume-based diets (Schwab, 1995). He also reported that providing adequate lysine for growing ruminants is more challenging for several reasons: 1) decreased lysine concentrations in the rumen undegradable protein (RUP) after passing the rumen due to rumen fermentation, 2) the digestibility of lysine in the intestine is lower than other AA and 3) greater sensitivity of lysine to heat or chemical treatments. Intensive research trials were conducted on rumen-protected methionine and lesser research was reported on rumenprotected lysine due to increased cost of production and instability (Swanepoel et al., 2010). Elwakeel et al. (2012) evaluated the bioavailability of lysine from rumen-protected hydroxyl methyl lysine (HML) by monitoring serum lysine concentration and estimated that lysine bioavailability reached $94 \%$ of that for the commercially available products by slope ratio analysis and concluded that rumen-protected HML might be effective for supplementing lysine to ruminants. Therefore, the objective of the current study was to assess the efficiency of the rumen-protected form of lysine (HML) in sheep growth, nutrient digestibility, nitrogen balance and some blood parameters in growing Barki sheep.

\section{MATERIALS AND METHODS}

The experiments were conducted at the Milk Production Project belonging to the Department of Animal and Fish Production, Faculty of Agriculture, Alexandria University. All samples were analysed at the laboratory of Animal Nutrition at the same department.

Two experiments were conducted to study the effect of HML (protected lysine) on growth performance, blood parameters, nitrogen retention and apparent nutrient digestibility compared to free lysine (lysine- $\mathrm{HCl}$ ) as positive control and no lysine as negative control.

\section{Growth trial:}

\section{Animals and housing managements:}

Fifteen Barki lambs with mean initial body weight $29.8 \pm 0.76 \mathrm{~kg}$ were randomly assigned equally to three treatments. Treatment 1), diet supplemented with protected lysine (P-LYS) to provide $3 \mathrm{~g}$ of total lysine; treatment 2), diet supplemented with free lysine (F-LYS) to provide $3 \mathrm{~g}$ of total lysine (positive control) and treatment 3), basal diet (not supplemented, negative control (CTR)). Lambs were kept in cement crats for 14 days prior to being subjected to treatments for dietary adaptation. After adaptation, lambs were individually weighed and returned to their crats where treatments were administered for 10 weeks. Lambs had free access to fresh drinking water.

\section{Diets and feeding managements:}

Lambs were offered 50:50 roughage to concentrate in equal portions twice a day (7.00 and 14.00) at about $3.5 \%$ of their body weight. The chemical composition of the basal diet is shown in Table 1. Hydroxy methyl lysine containing $10.4 \%$ nitrogen was manufactured in our laboratory as described by Elwakeel et al. (2012). Protected lysine and free lysine were weighed to provide $3 \mathrm{~g}$ lysine/day and were mixed with the concentrate and offered to the lambs first to ensure the intake of all lysine then roughages were offered. The amount of feed offered and refused was weighed and recorded daily.

\section{Measurements and sampling procedures:}

Body weights of lambs were determined biweekly before feeding. Blood samples $(10 \mathrm{~mL})$ were collected by jugular venepuncture from all lambs biweekly into plain vacuum tubes (vacutainer ${ }^{\circledR}$, Becton Dickinson, Rutherford, NJ, USA) before morning feeding with 20-gauge needles during manual restraint of the lambs.

Blood samples were placed on ice directly after collection, transferred to the lab, then were centrifuged for $20 \mathrm{~min}$ at $3000 \mathrm{rpm}$ and the harvested serum samples were then stored at $-20^{\circ} \mathrm{C}$ for later analysis. Serum biochemical constituents including total protein, albumin, glucose, cholesterol, urea and triglycerides were determined using commercial colorimetric kits (Stanbio Diagnostic Company, Germany). Globulin content of each serum sample was obtained by subtracting albumin contents from the serum total protein concentration. Rumen liquor was collected from each animal biweekly $3 \mathrm{~h}$ after feeding by oesophageal tube and was filtered through 4 layers of cheese cloth and $\mathrm{pH}$ was measured in fresh samples then samples were frozen at $-20^{\circ} \mathrm{C}$ for later analysis for ammonia concentrations and protozoal count. 
Egyptian J. Nutrition and Feeds (2018)

Table (1): Ingredients and chemical composition of concentrate mixture and peanut hay.

\begin{tabular}{|c|c|c|}
\hline Item & Concentrate mixture & Peanut hay \\
\hline \multicolumn{3}{|c|}{ Ingredients composition $(\mathrm{g} / \mathrm{kg})$} \\
\hline Yellow corn & 415 & ----- \\
\hline Wheat barn & 400 & ----- \\
\hline Soybean meal & 150 & ------ \\
\hline limestone & 20 & ------ \\
\hline Sodium chloride & 10 & ------ \\
\hline \multirow[t]{2}{*}{ Trace mineral* } & 5 & ------ \\
\hline & Total & 1000 \\
\hline \multicolumn{3}{|c|}{ Chemical composition $(\mathrm{g} / \mathrm{kg}) \quad$ (determined) } \\
\hline Dry matter & 957 & 855 \\
\hline Organic matter & 889 & 813 \\
\hline Crude protein & 143 & 98.9 \\
\hline Neutral detergent fibre & 435 & 575 \\
\hline Acid detergent fibre & 218 & 419.8 \\
\hline
\end{tabular}

\section{Digestibility and nitrogen balance trial:}

Animals: During the last seven consecutive days, 12 lambs were selected from the growth trial and were continued to receive the same diet and treatment for more 7 days. The lambs were kept in metabolic cages and had a free access to fresh drinking water. The diet were offered twice daily as described in the first experiment and because animals were already adapted to the diet through the growth study, the experimental period was limited to seven days of which five consecutive days were for collecting feed, feces and urine samples. Feed offered and refused were weighed and recorded daily.

The total amount of feces excreted was weighed daily for each animal and only $10 \%$ of total quantity was stored in refrigerator at $5^{\circ} \mathrm{C}$ throughout the collection period. After the completion of the experiment, feces samples were mixed thoroughly and $1000 \mathrm{gm}$ of this mixture was dried at $60^{\circ} \mathrm{C}$ for $72 \mathrm{~h}$. in a forced air oven, ground through $1 \mathrm{~mm}$ screen and stored for later analysis for DM and $\mathrm{N}$ content. Urine sample from each lamb was collected daily in plastic buckets containing $100 \mathrm{ml}$ of $10 \%$ sulphuric acid to prevent nitrogen loss as ammonia and a $10 \%$ of urine samples were frozen at $-20^{\circ} \mathrm{C}$ for later determination of $\mathrm{N}$ content.

\section{Sample analysis:}

Duplicate samples of the composite feed and feces were used for DM, OM determination (A.O.A.C, 2006). Duplicate samples of the urine, feces and the diet were used for Kjeldahl nitrogen analysis. NDF and ADF were determined by the method of Van Soest et al. (1991) with heat-stable amylase. Both NDF and ADF were assayed on DM basis and expressed without inclusion of ash. Hemicellulose content was measured by subtracting ADF from NDF.

\section{Statistical analysis:}

The statistical analysis of the growth data and blood metabolites was performed by repeated measurements using the mixed procedure (SAS, windows 9.0) with a model that contained effect of treatment, time (wk.), treatment $\times$ time. The repeated measurement was the time and the subject of repeated measurement was the animal. The data for digestibility was analysed using mixed procedure (SAS, windows 9.0) with a model that contained animals as random effect and treatment as fixed effect. Differences between treatments were declared significant at $\mathrm{P}<0.05$ and tendency at $\mathrm{P}<0.14$. All treatments means are presented as least square means in the present study. 


\section{Elwakeel et al.}

\section{RESULTS AND DISCUSSION}

\section{Growth performance, feed intake and feed conversion ratio:}

Effect of dietary rumen-protected lysine HML supplementation on ADG, DMI and FCR are presented in Table (2). Treatments had no effect on final body weight, ADG, DMI, or FCR. No interaction was detected between treatments and time on DMI or FCR. Whereas, a weak tendency interaction was detected between treatment and time on ADG $(\mathrm{P}=0.07)$. The reason for tendency of interaction is that P-LYS increased ADG (318 g/day) only in the last $2 \mathrm{wk}$. compared to control $(191 \mathrm{~g} / \mathrm{d} ; \mathrm{P}<0.05)$, however, $\mathrm{P}-\mathrm{LYS}$ tended to increase ADG compared to F-LYS (222 g/d; P=0.05) in wk. 10 (Figure 1). In the present study, the predicted lysine content of the basal diet was $5.5 \mathrm{~g} / \mathrm{kg}$ diet and the predicted metabolizable lysine for that basal diet, which is intestinally available for absorption, was $5.2 \mathrm{~g} / \mathrm{kg}$ diet.

Table (2): Effects of free lysine (F-LYS) and protected lysine (P-LYS) supplementation on initial and final body weight, average daily gain (ADG), dry matter intake (DMI) and feed conversion ratio $(F C R)$ in growing lambs.

\begin{tabular}{|c|c|c|c|c|c|c|c|}
\hline \multirow{2}{*}{ Item } & \multicolumn{3}{|c|}{ Treatments $^{1}$} & \multirow{2}{*}{ P-SEM* } & \multicolumn{3}{|l|}{ P-value } \\
\hline & Control & F-LYS & P-LYS & & Treatment & Time & Treatment $\times$ Time \\
\hline \multicolumn{8}{|c|}{ Body weight (kg) } \\
\hline Initial & 29.68 & 29.87 & 31.38 & 0.76 & 0.679 & - & - \\
\hline Final & 41.76 & 42.17 & 44.76 & 0.84 & 0.342 & - & - \\
\hline $\mathrm{ADG}(\mathrm{g})$ & 172.6 & 175.7 & 187.7 & $13^{*}$ & 0.776 & 0.003 & 0.067 \\
\hline DMI (g/d) & 1170 & 1222 & 1279 & $47.89^{*}$ & 0.343 & $<0.001$ & 0.999 \\
\hline FCR & 6.8 & 7 & 6.8 & $0.92^{*}$ & 0.431 & 0.101 & 0.301 \\
\hline
\end{tabular}

${ }^{T}$ F-LYS and hydroxy methyl lysine ( $P$-LYS) provide 3 g/day total lysine. P-SEM: Pooled standard error of the mean.

"to get SEM for P-LYS multiply SEM by 1.12.

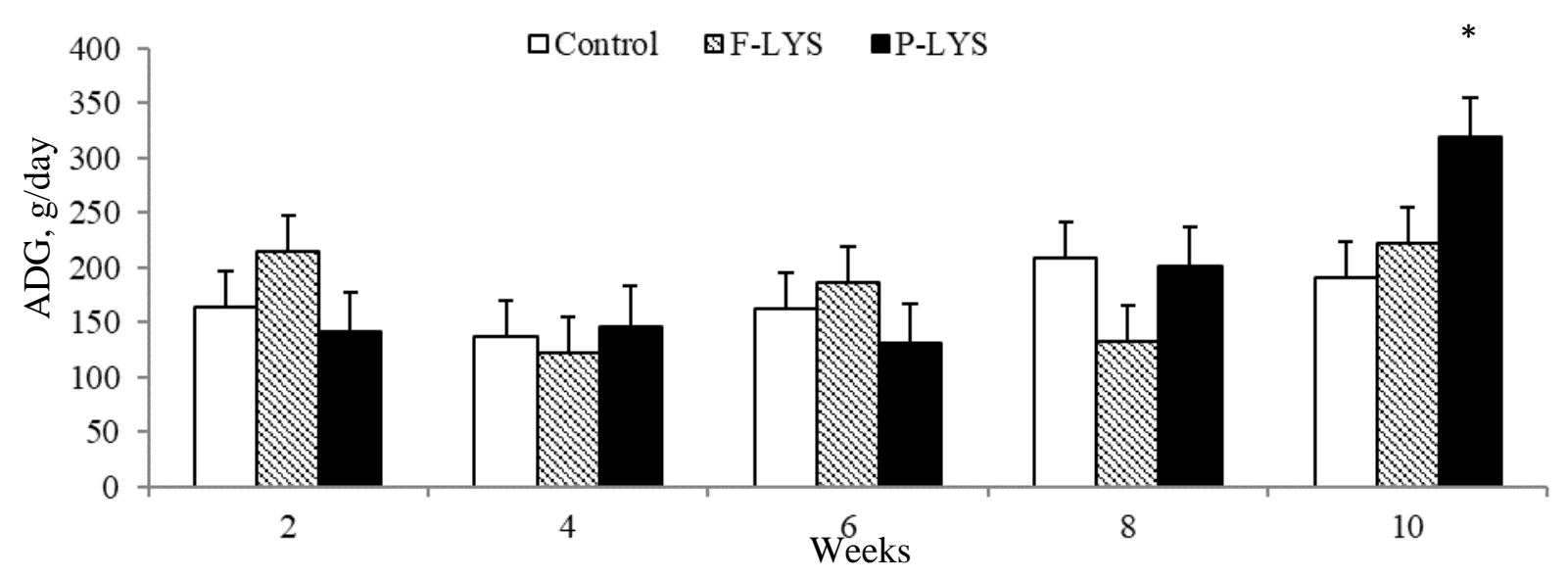

Figure (1): Treatment $\times$ time (wk.) interaction of free lysine (F-LYS) and protected lysine (P-LYS) supplementation on average daily gain (ADG) in growing lambs.

*P-LYS $(P<0.05)$ increased ADG compared to F-LYS and control during the last 2 weeks

The three grams of lysine in P-LYS that is assumed to be $80 \%$ available for absorption would increase intestinally available lysine to $7.6 \mathrm{~g}$ in the P-LYS receiving group. The predicted rumen undegradable protein 
(RUP) in the basal diet of the current study based on NRC (2001) calculation was 26\%. The high-predicted rumen degradable protein (74\%, RDP) was intended to maximize microbial crude protein (MCP) synthesis in order to ensure that no other AA was limiting for animal growth. However, MCP could be synthesized more than predicted and contributes for higher lysine concentration in the metabolizable protein (MP), therefore treatments failed to induce positive results in response to P-LYS supplementation.

Elwakeel et al. (2012) reported that rumen-protected HML was highly protected when evaluated on ewes by measuring blood lysine concentration as an indicator of lysine bioavailability from HML and recommended the use of HML as a source of ruminally protected

lysine for ruminants. The HML is the derivative of lysine by the reaction of lysine-HCL with formaldehyde in an aqueous solution of water containing calcium hydroxide (Bertram et al. 1978). Richardson (1976) reported that the combination of HML and HMM improved N retention, daily gain compared to control. However, when Kenna and Schwab (1981) evaluated the effect of supplementation of hydroxyl methyl methionine (HMM) and HML either alone or in combined on feed intake, milk production, and milk composition of dairy cattle fed corn-based ratio, they reported that there was no effect compared to control. The authors delineated that the lack of response could be due to the release of lysine from its protected form as a result of mixing HML with acidic diet (corn silage). In the current study, P-LYS was mixed with the concentrate diet that was not acidic to ensure that the product is not released. We predicted that P-LYS should improve lambs performance when supplemented to the diet that intended to be deficient in lysine.

Although the overall effect of treatment on ADG was not significant, introducing P-LYS to growing lambs significantly increased their ADG in the last $2 \mathrm{wk}$. of the growth trial compared to control and F-LYS groups. The reason for not obtaining a positive response after P-LYS supplementation and the response appeared significantly only at the last $2 \mathrm{wk}$. is hard to explain, but it could be either due to the intestinal availability of lysine from P-LYS increased when the animals grow older as a result of increasing abomasal HCL production as animals grow up. Also, It is important to mention that lysine utilization for protein deposition is affected by the availability of other amino acids (Greenwood and Titgemeyer, 2000) where there is still possibility that other amino acids were limited in the basal diet of current study but the lamb's requirement for these AA started to decline at the last $2 \mathrm{wk}$. of the experiment, making lysine is the only deficient AA. This could be another possible explanation for increased ADG in last 2 wk. only.

\section{Blood Parameters:}

Data for effect of treatment on serum total protein (TP), albumin (Alb), globulin (Glob), urea, triglycerides (TG), cholesterol $(\mathrm{CH})$ and glucose $(\mathrm{G})$ are shown in Table 3. There were no effects of TRT on TP, Alb, Glob, urea, TG, $\mathrm{CH}$ and G. No interaction was detected between treatment and time for TG, $\mathrm{CH}$ and $\mathrm{G}$. In the meantime, a tendency of interaction was detected between treatment and time for TP, Alb and Glob $(\mathrm{P}=0.06)$ and urea $(\mathrm{P}=0.07)$. P-LYS increased $(\mathrm{P}<0.05) \mathrm{TP}, \mathrm{Alb}$ and Glob in wk. 2 measurement compared to control and F-LYS groups (Figure 2). In addition, P-LYS reduced $(\mathrm{P}<0.05)$ urea on wk. 10 compared to control and F-LYS (Figure 2).

Table (3): Effects of free lysine (F-LYS) and protected lysine (P-LYS) supplementation on serum biochemical parameters in growing lambs.

\begin{tabular}{lccccccc}
\hline \multirow{2}{*}{ Item } & \multicolumn{3}{c}{ Treatment $^{1}$} & \multirow{2}{*}{ P-SEM } & \multicolumn{3}{c}{ P-value } \\
\cline { 2 - 3 } & Control & F-LYS & P-LYS & & Treatment & Time & Treatment×Time \\
\hline Total protein, g/dL & 9.35 & 8.72 & 9.25 & 0.42 & 0.541 & 0.553 & 0.056 \\
Albumin, g/dL & 3.88 & 3.62 & 3.84 & 0.17 & 0.543 & 0.579 & 0.055 \\
Globulin, g/dL & 5.47 & 5.1 & 5.42 & 0.25 & 0.535 & 0.551 & 0.059 \\
Urea, mg/dL & 91.79 & 94.69 & 89.6 & 2.46 & 0.371 & 0.001 & 0.074 \\
Triglycerides, mg/dL & 76.8 & 85.35 & 90.46 & 6.74 & 0.358 & 0.001 & 0.935 \\
Cholesterol, mg/dL & 64.17 & 69.13 & 66.32 & 3.23 & 0.567 & 0.742 & 0.298 \\
Glucose, g/dL & 96.5 & 102.6 & 90.5 & 5.5 & 0.225 & 0.042 & 0.319 \\
\hline
\end{tabular}

${ }^{I} \mathrm{~F}$-LYS and hydroxy methyl lysine (P-LYS) provide $3 \mathrm{~g} / \mathrm{d}$ total lysine.

P-SEM: Pooled standard error of the mean. 


\section{Elwakeel et al.}

Serum TP, Alb and Glob increased $(\mathrm{P}<0.05)$ in week two only for P-LYS compared to control and FLYS groups, with no clear explanation for the different effects at different times. However, the overall effect of treatments on TP, Alb and Glob were not significant $(\mathrm{P}>0.05)$. In agreement with the current results, supplementing diets with rumen protected lysine and methionine did not affect blood Alb and Glob concentration in female calves (Sai et al., 2014). Also, Singh et al. (2015) found no effect of protected methionine and lysine on TP, Alb and Glob. The increase in the ADG in the last two wks. with P-LYS supplementation in the growth study is sequential to lower serum urea in that period which indicating that lysine was used for protein deposition and hence reduced AA catabolism which appeared as reduction in serum urea (Hussein et al., 2016). These results agree with Hussein et al. (2016) who found that lysine infusion reduced serum urea. He also found no effect of abomasal infusion of lysine on blood glucose or insulin in growing steers. Same results of blood glucose were obtained by Sai et al. (2014) when they fed rumen protected lysine and methionine to calves.
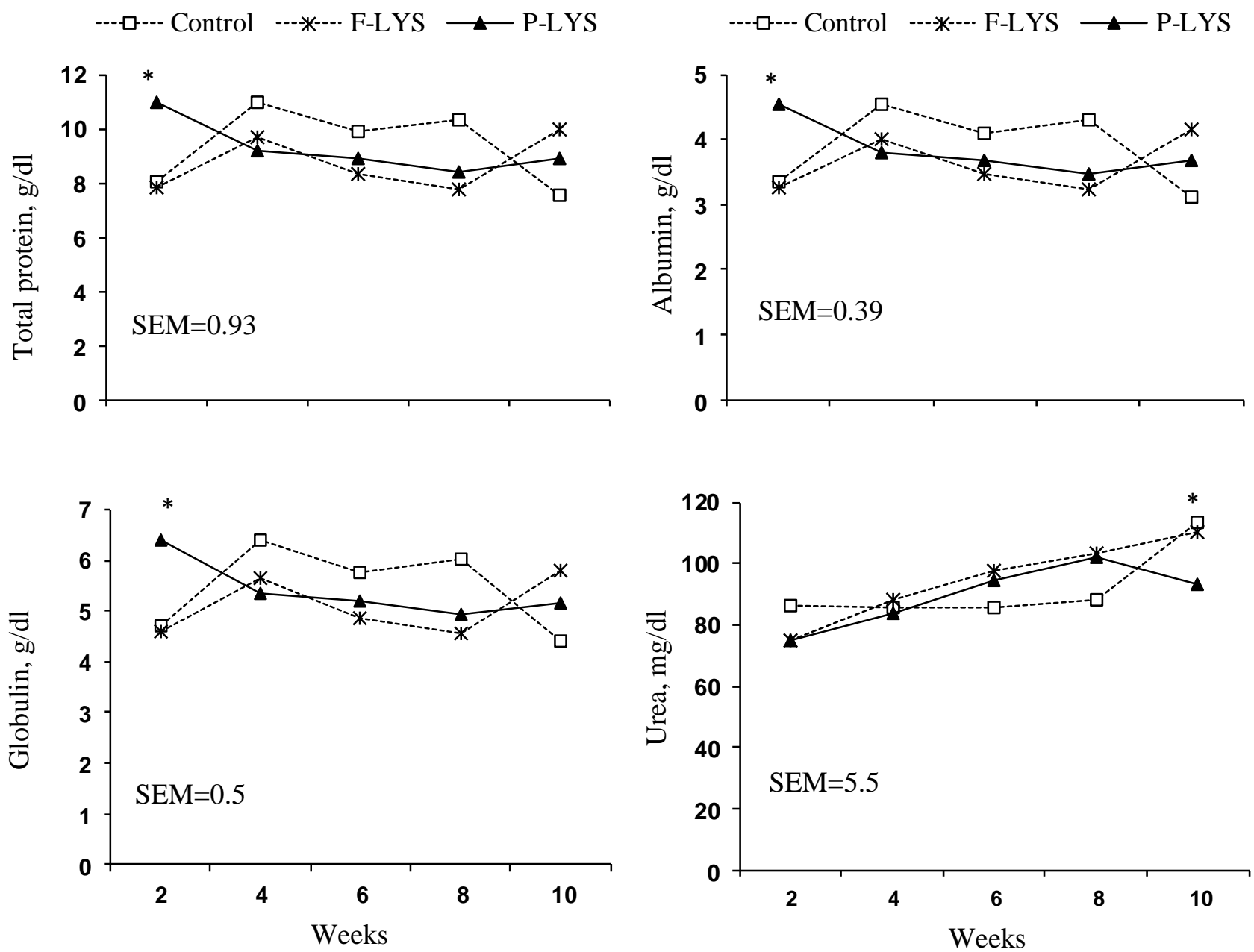

Figure (2): Treatment $\times$ time (wk.) interaction of free lysine (F-LYS) and protected lysine (P-LYS) supplementation on total protein (TP), albumin (Alb), globulin (Glob) and urea (U) in growing lambs.

* P-LYS $(P<0.05)$ increased TP, Alb and Glob compared to F-LYS and control in the first 2 weeks. * P-LYS $(P<0.05)$ decreased urea compared to F-LYS and control in the last 2 weeks. 


\section{Rumen fermentation and apparent nutrients digestibility:}

The effect of P-LYS supplementation on rumen $\mathrm{pH}$, ammonia-N and protozoa are shown in Table (4). There were no effect of treatments on rumen $\mathrm{pH}$, ammonia- $\mathrm{N}$ and protozoa count. No interaction was detected between TRT and time for rumen $\mathrm{pH}, \mathrm{NH} 4$ and protozoa count. Apparent digestibility of DM, OM, $\mathrm{CP}, \mathrm{NDF}$, ADF, cellulose, hemicellulose and lignin, were not affected $(\mathrm{P}>0.05)$ by F-LYS and P-LYS supplementations compared to the control (Table 5).

Table (4): Effects of free lysine (F-LYS) and protected lysine (P-LYS) supplementation on rumen fermentation parameters in growing lambs.

\begin{tabular}{|c|c|c|c|c|c|c|c|}
\hline \multirow{2}{*}{ Item } & \multicolumn{3}{|c|}{ Treatment $^{1}$} & \multirow{2}{*}{ P-SEM } & \multicolumn{3}{|c|}{ P-value } \\
\hline & Control & F-LYS & P-LYS & & Treatment & Time & Treatment×Time \\
\hline $\mathrm{pH}$ & 6.47 & 6.48 & 6.58 & 0.04 & 0.136 & $<0.001$ & 0.940 \\
\hline $\begin{array}{l}\mathrm{NH}_{3}-\mathrm{N} \\
\mathrm{mg} / \mathrm{dl}^{\mathrm{b}}\end{array}$ & 23.1 & 22.4 & 18.3 & 1.75 & 0.152 & $<0.001$ & 0.794 \\
\hline $\begin{array}{l}\text { Protozoa, } \\
\times 10^{5} / \mathrm{mL}\end{array}$ & 3.45 & 3.49 & 3.81 & 0.22 & 0.467 & $<0.001$ & 0.545 \\
\hline
\end{tabular}

Table (5): Effects of free lysine (F-LYS) and protected lysine (P-LYS) supplementation on apparent nutrient digestibility $(\mathrm{g} / \mathrm{kg})$ in sheep.

\begin{tabular}{|c|c|c|c|c|c|}
\hline \multirow{2}{*}{ Item } & \multicolumn{3}{|c|}{ Treatment $^{1}$} & \multirow{2}{*}{$\mathrm{P} \mathrm{SEM}^{4}$} & \multirow{2}{*}{ P-value } \\
\hline & Control & F-LYS & P-LYS & & \\
\hline Dry matter & 634 & 685 & 672 & 20.9 & 0.6263 \\
\hline Organic matter & 697 & 741 & 742 & 14.4 & 0.382 \\
\hline Crude protein & 624 & 670 & 663 & 18.8 & 0.6016 \\
\hline $\mathrm{NDF}^{2}$ & 588 & 622 & 650 & 17.3 & 0.3739 \\
\hline $\mathrm{ADF}^{3}$ & 572 & 593 & 638 & 16.7 & 0.2846 \\
\hline Cellulose & 835 & 860 & 861 & 34.6 & 0.3739 \\
\hline hemicellulose & 157 & 213 & 268 & 8.2 & 0.4633 \\
\hline
\end{tabular}

${ }^{I} F$-LYS and hydroxy methyl lysine ( $P$-LYS) provide $3 g /$ d total lysine.

${ }^{2} N D F$ : neutral detergent fiber; ${ }^{3} A D F$ : acid detergent fiber.

${ }^{4}$ P-SEM: Pooled standard error of the mean.

Treatments with P-LYS or F-LYS did not affect rumen fermentation as evident in unaffected ruminal $\mathrm{pH}$, ammonia concentration or protozoa number. Also, unchanged digestibility of DM, OM, CP, ADF, NDF, cellulose and hemicellulose (Table 6) in response to P-LYS supplementation indicated that P-LYS did not affect ruminal fermentation and nutrient digestibility in the concentration used in the current study. In accordance to these results, Hussein et al. (2016) reported no effect of infused lysine in OM and DM digestibility of diet-deficient in lysine when given to growing steers. Elwakeel et al. (2012) reported that high concentrations of P-LYS that were used in-vitro had negative effect on ruminal fermentation when used at concentrations of 25 and $50 \mathrm{mM}$. Certainly, these concentrations were much higher than that was used in the current study, but our results indicated that the P-LYS product is not affecting rumen fermentation or nutrients digestibility negatively.

\section{Nitrogen intake, feces and urine $N, N$ balance and retained $N$ :}

The effect of supplementing P-LYS on nitrogen intake, feces and urine nitrogen, nitrogen balance and retained nitrogen as percent of $\mathrm{N}$ intake are shown in Table 6. Lysine supplementation either in the protected (P-LYS) or free (F-LYS) form did not affect $\mathrm{N}$ intake, feces $\mathrm{N}(\mathrm{P}=0.57)$, and urine $\mathrm{N}(\mathrm{P}=0.16)$. Although it is not significant, lambs that received F-LYS execrated slightly more nitrogen in the urine $(8.43 \mathrm{~g} / \mathrm{d})$ compared to CTR $(6.86 \mathrm{~g} / \mathrm{d})$ and P-LYS $(5.74 \mathrm{~g} / \mathrm{d})$ lambs. There was a tendency effect of treatment on NB 


\section{Elwakeel et al.}

$(\mathrm{P}=0.096)$ where treatment with HML increased NB from 4.8 and $5.01 \mathrm{~g} / \mathrm{d}$ in CTR and F-LYS, respectively to $7.1 \mathrm{~g} / \mathrm{d}$ in the $\mathrm{P}-\mathrm{LYS}$ treatment. Retained $\mathrm{N}$ as percentage of $\mathrm{N}$ intake tend to increase $(\mathrm{P}=0.06)$ in P-LYS group (37.9\%) compared to control and F-LYS (25.59 vs. $25.01 \%$, respectively).

Table (6): Effects of free lysine (F-LYS) and protected lysine (P-LYS) supplementation on nitrogen intake, nitrogen in feces and urine and nitrogen balance in growing lambs.

\begin{tabular}{lccccc}
\hline \multirow{2}{*}{ Item } & \multicolumn{3}{c}{ Treatment $^{1}$} & \multirow{2}{*}{ P-SEM } & \multirow{2}{*}{ P-value } \\
\cline { 2 - 4 } & Control & F-LYS & P-LYS & & 0.44 \\
Nitrogen intake, g/d & 18.81 & 19.88 & 18.82 & 0.569 \\
Feces nitrogen, g/d & 7.17 & 6.44 & 6.25 & 0.35 & 0.576 \\
Urine nitrogen, g/d & 6.86 & 8.43 & 5.47 & 0.63 & 0.158 \\
Nitrogen balance, g/d & 4.78 & 5.01 & 7.1 & 0.49 & 0.096 \\
Retained N,\% of NI & 25.59 & 25.01 & 37.87 & 2.6 & 0.0597 \\
\hline
\end{tabular}

${ }^{I} \mathrm{~F}$-LYS and hydroxy methyl lysine ( $P$-LYS) provide $3 \mathrm{~g} / \mathrm{d}$ total lysine.

P-SEM: standard error of the mean.

The tendency of improvement in NB and retained $\mathrm{N}$ measurements as percentage of NI by P-LYS receiving lambs could be attributed to the numerically less nitrogen that was excreted in urine compared to control though the difference was not significant. Such improvement in NB in the P-LYS group may indicate that the basal diet of our study was slightly deficient in lysine. Therefore, lysine was used for protein deposition. Many studies have shown that lysine supplementation either in protected form or abomasally infused, increased NB and reduced urine $\mathrm{N}$ when added to diets that are deficient in lysine (Oke et al., 1986; Brookes et al., 1973; Nimrick et al., 1970 and Hussein et al., 2016). The tendency to improve RN as percent of NI $(\mathrm{P}=0.05)$ is emphasized in the improvement in $\mathrm{ADG}$ in the last $2 \mathrm{wk}$. of growth trial.

\section{CONCLUSION}

The lack of response of P-LYS supplementation on animal performance in the current study might be due to either the higher contribution of MCP (74\% calculated based on NRC, 2001) in the MP which could provide adequate amount of lysine in MP or the deficiency of other AA in the basal diet that hinder protein deposition. Therefore, lysine AA was not limited for lambs grown under the diet used in this study. However, the improvement of ADG in the last 2 wk. of the growth trial with consequent reduction in serum urea in that period only, indicates that this product could be promising to improve animal performance under certain circumstances. More research is needed to study the efficiency of lysine utilization in growing lambs.

\section{ACKNOWLEDGEMENTS}

The authors are grateful to the support from the Department of Animal and Fish Production and the Milk Production Project, Faculty of Agriculture, Alexandria University.

\section{REFERENCES}

A.O.A.C. (2006). Official Methods of Analysis. $18^{\text {th }}$ Edition, Association of Official Analytical Chemists, Gaithers burgs, MD.

Bertram, H., R. Fahnenstich, H. Offermanns and H. Tanner (1978). Fodder for cows. United State Patent number 4, 073: 945. 
Brookes, I.M, F.N. Owens, R.E. Brown and U.S. Garrigus (1973). Amino Acids oxidation and plasma amino acid levels in sheep with abomasal infusions of graded amounts of lysine. J. Anim. Sci., 36: 965-970.

Elwakeel, E.A., E.C. Titgemeyer, B.R. Faris, D.W. Brake, A.M. Nour and M.E.A. Nasser (2012). Hydroxy methyl lysine is a source of bioavailable lysine for ruminants. J. Anim. Sci., 90: 3898-3904.

Greenwood R.H. and E.C. Titgemeyer (2000). Limiting amino acids for growing Holstein steers limit-fed soybean hull-based diets. J. Anim. Sci., 78: 1997-2004.

Hussein, A.H., E.D. Batista, M.D. Miesner and E.C. Titgemeyer (2016). Effect of ruminal ammonia supply on lysine utilization by growing steers. J. Anim. Sci., 94: 656-664.

Kenna, T.M. and C.G. Schwab (1981). Evaluation of N-hydroxy methyl-DL-methionine-Ca and di-hydroxy methyl-L-lysine-Ca in a blend corn based ration for lactation cows. J. Dairy Sci., 64: 775-781.

Merchen, N.R. and E.C. Titgemeyer (1992). Manipulation of amino acid supply to the growing ruminant. J. Anim. Sci., 70: 3238-3247.

National Research Council (NRC) (2001). Nutrient Requirements of Dairy Cattle. $6^{\text {th }}$ Ed. Nat. Acad. Sci., Washington D.C., USA.

Nimrick, K., E.E. Hatiefield, J. Kaminsk, and F.N. Owens (1970). Qualitative assessment of supplemental amino acid needs for growing lambs fed urea as the sole nitrogen source. J. Nutr., 100: 1293-1300.

Oke, B.O., S.C. Loerch and L.E. Deetz (1986). Effects of rumen-protected methionine and lysine on ruminant performance and nutrient metabolism. J. Anim. Sci., 62: 1101-1112.

Richardson, C.R. (1976). Limiting amino acids in growing ruminants. Ph.D. thesis. Univ. Illinois, Champaign-Urbana.

Richardson, C.R. and E.E. Hatfield (1978). The limiting amino acid in growing cattle. J. Anim. Sci., 46: 740-745.

Rulquin, H. and R. Verite (1993). Amino acid nutrition of dairy cows: Production effects and animal requirements. Page 55 in Recent Advances in Animal Production, Proc. 27th Univ. Nottingham Feed Manuf. Conf. P. C. Gainsworthy, ed. Nottingham Univ. Press, Nottingham, UK.

Sai, S., S.S. Thakur and N. Kewalrmani (2014). Effect of supplementation of rumen protected methionine plus lysine on growth performance, nutrient utilization and blood metabolites in calves. Indian J. Anim. Nutr., 31(1): 1-7.

Schwab, C.G. (1995). Protected proteins and amino acids for ruminants. Biotechnology in Animal Feed and Animal Feeding. R. J. Wallace and A. Chesson, ed. VCH Verlagsgesellschaft, Weinheim (Federal Republic of Germany) and VCH publishers Inc., New York, NY., 115-141.

Schwab, C.G., C.K. Bozak, N.L. Whitehouse and V.M. Oslon (1992). Amino acid limitation and flow to the duodenum at four stages of lactation. 2. Extent of lysine limitation. J. Dairy Sci., 75: 3503-3518.

Singh, J.K., D. Roy, V. Kumar, M. Kumar and R. Sirohi (2015). Effect of supplementing rumen protected methionine and lysine of nutrient utilization, growth and blood biochemical parameters in Hariana heifers. Indian J. Anim. Nutr., 32(2): 187-191.

Swanepoel, N., P.H. Robinson and L.J. Erasmus (2010). Amino acid needs of lactating dairy cows: Impact of feeding lysine in a ruminally protected form on productivity of lactating dairy cows. Anim. Feed Sci. Technol., 157: 79-94.

Titgemeyer, E.C. (2003). Amino acid utilization by growing and finishing ruminants. In: J. P. F. D’Mello, editor, Amino acids in animal nutrition. $2^{\text {nd }}$ ed. CAB Int., Wallingford, UK. p., 329-346.

Van Soest, P.J., J.B. Robertson and B.A. Lewis (1991). Methods for dietary fiber, neutral detergent fiber, and non-starch polysaccharides in relation to animal nutrition. J. Dairy Sci., 74: 3583-3597. 


\title{
Elwakeel et al.
}

\section{تأثير إضافة الليسين المحمي (هيدروكسي ميثيل ليسين) على الأداء وبعض معايير الام لحملان البرقي}

\author{
إيمان علي الوكيل1 و هاني لحمح الزيات وعمر صلاح مرسي²

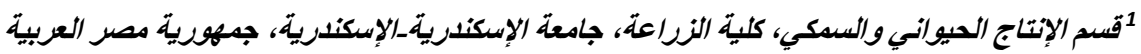

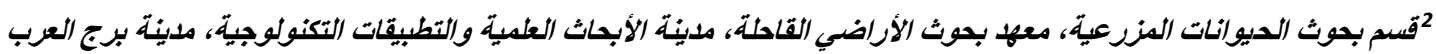

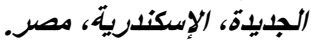

تم إجراء تجربتين، تجربة نمو وتجربة هضم، لمعرفة تأثير إضافة الحامض الأميني ليسين في صورة محمية من تخمر ات الكرش على الكي

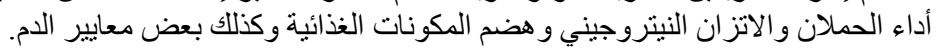

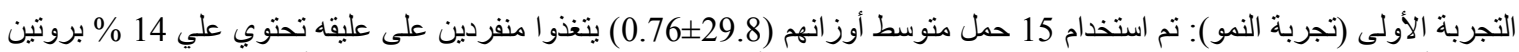

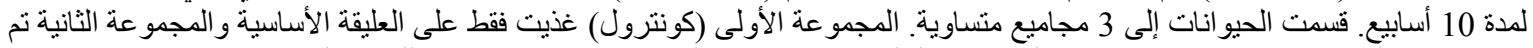

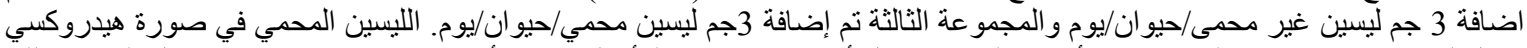

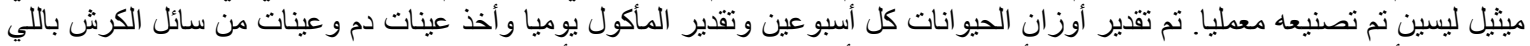

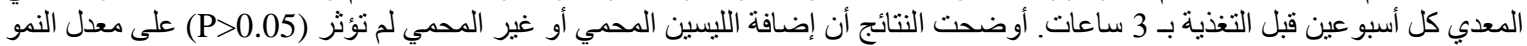

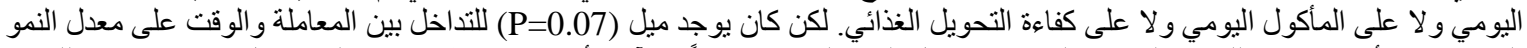

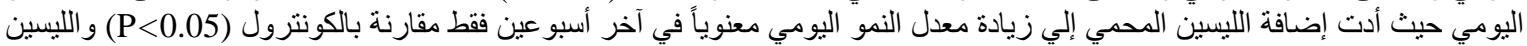

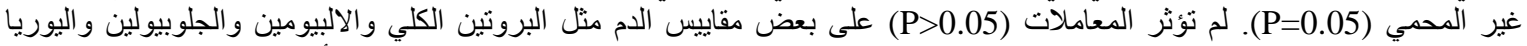

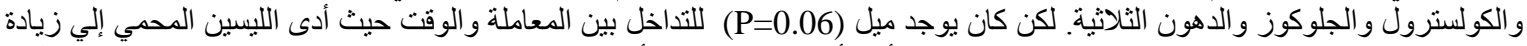

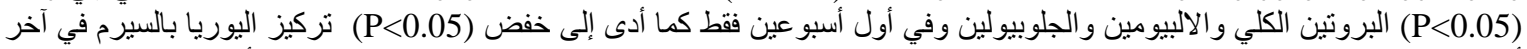

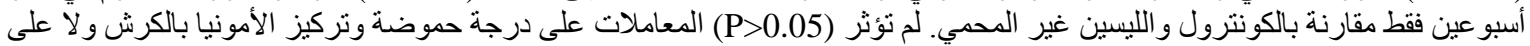
أعداد البروتوزوا.

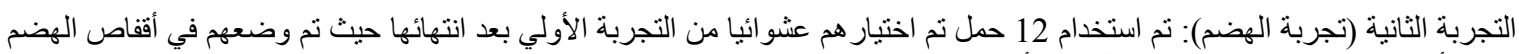

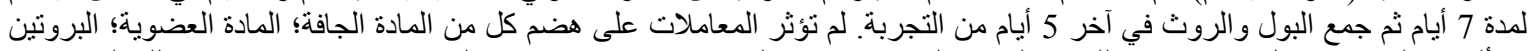

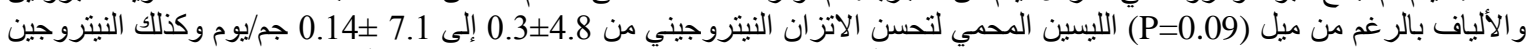

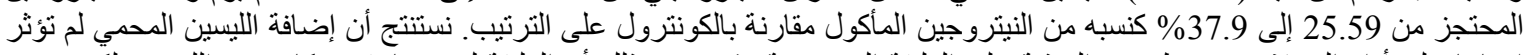

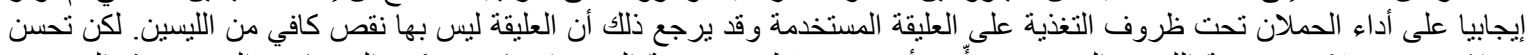

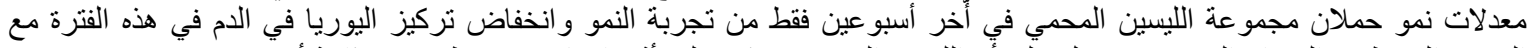

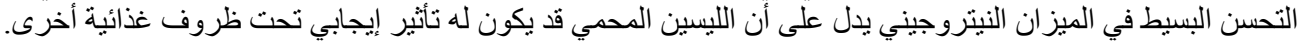

